\title{
Imágenes y sonidos del Wall Mapu. El proyecto de descolonización del universo visual y sonoro del Pueblo Mapuche
}

\author{
Images and sounds from Wall Mapu. The proyect of \\ decolonization of the visual and acoustic universe of Mapuche \\ People
}

\author{
ELISA GARCÍA MINGO
}

Universidad Complutense de Madrid elisagmingo@gmail.com (ESPAÑA)

Recibido: 04.07.2016

Aceptado: 07.09.2016

\section{RESUMEN}

La historia del vídeo indígena y de las radios indígenas en el Abya Yala (América Latina) es una historia de descolonización de la palabra y la imagen. La propuesta de descolonización mediática que han elevado los pueblos indígenas del Abya Yala, basada en la producción de textos verbo-audio-visuales desde su propia cosmovisión y proponiendo nuevos lenguajes visuales, nos permiten (re)pensar sobre las nuevas (y antiguas) formas de ver y las identidades visuales divergentes. A su vez, las radios indígenas han permitido a las comunidades crear un espacio para elevar la voz colectiva y proyectarla en el radioespectro creando paisajes sonoros descolonizados mediante nuevos (y antiguos) lenguajes sonoros que se adecuan a una formas de escuchar propias de su cosmovisión y que permiten revisar la matriz epistémica que ha conformado la mirada y el oído occidental, que en muchas ocasiones han constituido una mirada colonial y colonizadora sobre los Pueblos Indígenas. En las dos últimas décadas, el Pueblo Mapuche ha creado proyectos mediáticos que han producido una interferencia indígena Cárcamo-Huechante (2013) en una "mediasfera" (Appadurai, 1995) colonizado que estaba monopolizado por los estados criollos que han construido la memoria de los nuevos estados sobre una identidad no indígena. Este artículo contempla la dimensión política de estos proyectos, ya que la producción audiovisual tiene demostrada capacidad para empoderar a los sujetos subalternizados y permitirles desafiar la violencia de la representación que han experimentado. 


\title{
PALABRAS CLAVE
}

Medios indígenas, políticas de la representación, identidad visual, paisaje sonoro, Abya Yala

\begin{abstract}
The history of indigenous video and in Abya Yala (Latin America) is the story of the struggle to decolonize the mediascape. Indigenous peoples in Abya Yala have raised a proposal of decolonization of the audiovisual production, creating their own films and soundscapes from their worldview, and thus have proposed new visual and acoustic languages. This phenomenon allows us to (re) think about the new (and old) ways to see and the divergent visual identities. Also, indigenous radios have allowed communities to create space where they can raise their collective voice and project it on the radio spectrum creating decolonized soundscapes. In the last two decades, the Mapuche people has created media projects that have produced an indigenous interference Cárcamo-Huechante (2013) in a colonized mediascape (Appadurai, 1995) that has been traditionally monopolized by the Chilean state, that has built its memory and identity as white and non-indigenous. This article considers the political dimension of these projects because audiovisual production has proven to be an effective tool to empower individuals and to allow subalterns to challenge the persistent violence of representation they have experienced.
\end{abstract}

\section{KEY WORDS}

Indigenous media, politics of representation, visual identity, soundscape, Abya Yala

\section{A MODO DE INTRODUCCIÓN: UNAS NOTAS SOBRE EL PROYECTO AUDIO(Y)VISUAL INDÍGENA}

En las últimas décadas, el movimiento político del Pueblo Mapuche en Chile ha ido articulando, tanto a nivel nacional como a nivel internacional, distintas estrategias en su lucha por los derechos colectivos. Este trabajo indaga sobre el uso de los medios de comunicación que está haciendo este colectivo, por considerarlo un caso destacado en el marco de la propuesta de descolonización del universo audiovisual que están haciendo los Pueblos Indígenas en Abya Yala ${ }^{1}$. La reflexión que sigue pretende expandir la aproximación analítica a la imagen y al sonido como fuentes de conocimiento de lo social al revisar las

${ }^{1}$ Denominación de América Latina por el movimiento panindígena latinoamericano. En el idioma Kuna significa: "Tierra en plena madurez" 
maneras en las que algunos colectivos no hegemónicos cuestionan, conciben y elaboran los códigos culturales implícitos en la creación de textos verboaudio-visuales. Este aspecto es relevante porque no podemos olvidar que investigar con documentos audio(y)visuales implica dar sentido a los códigos de representación, de saber y de percepción implícitos en una cultura Serrano y Zurdo (2012: 222).

Cuando investigamos con y sobre las imágenes no podemos obviar el hecho de que los grandes proyectos políticos de dominación han tenido una dimensión visual. De la misma manera, los proyectos de emancipación también tienen dicha faceta. En mayor o menor medida y con procesos bien diversos, los Pueblos Indígenas, están inmersos en la tarea de poner fin al régimen de dominación audiovisual al que le sometió Occidente, tratando de subvertir el encubrimiento y la distorsión de las sociedades "conquistadas", que comenzó con la cultura de la imagen sobre la cual se asentó el poder colonial, plasmada en cuadros, retablos y todo un corpus iconográfico, arquitectónico, ceremonial y festivo Rivera Zea (2013:9). Todas estas instancias de representación, así como otras tecnologías del saber ocular -archivos de Indias, cartografía, libros de viajeroscumplieron una función determinante para crear una nueva geopolítica del ver Barriendos (2008) que creó tanto una mirada colonizadora como una mirada colonizada. La colonialidad del ver se cristalizó en los siglos XIX y XX gracias al relato etnográfico, el cine documental y la fotografía de autor y sólo hoy está siendo deconstruida: por los propios sujetos representados.

La emergencia indígena que se ha producido en América Latina desde los años 90 Bengoa (2000) ha cambiado las reglas del juego de la representación: ahora "los indios" (e incluso "las indias") se piensan, se imaginan y se representan a sí mismos, sin necesidad de mediación. Hoy, los movimientos sociales indígenas, en un acto de resistencia simbólica ${ }^{2}$ devuelven a los españoles los espejos que les fueron entregados en el siglo XVI y, a su vez, reivindican el fin del juego de espejos colonial, aquellos en los que al mirarse encontraban invisibilidad o distorsión. Los Pueblos Indígenas, en tanto que movimientos sociales, han puesto en crisis las formas de organización social, el pensamiento y en la sensibilidad de la modernidad criolla. Levantamientos indígena como el que protagonizó el Ejército Zapatista de Liberación Nacional (EZLN) en enero de 1994, ha servido como espejos ${ }^{3}$ cóncavos para las $^{2}$ sociedades criollas latinoamericanas Reguillo (2000: 68), quienes asisten,

2 El líder indígena del Pueblo Misak de Colombia, Lorenzo Muelas, hizo un pronunciamiento enfrente de la embajada de España en Colombia, devolviendo simbólicamente los espejos (Ossa, 2013: 39)

3 Jesús de Miguel y Omar Ponce plantean tres metáforas para comprender el papel de la fotografía en relación a su trabajo sobre representación del Mundo: la fotografía-ventana, la fotografía-espejo y la fotografía-regla (1999:88). Para esta reflexión, me resulta sugerente la metáfora del espejo, la cual afirma que las imágenes reflejan el punto de vista, los códigos culturales, los intereses, los temores y los afectos del sujeto que crea la imagen Serrano y Zurdo (2012: 225). Por otro lado, es un espejo, porque entra en juego no sólo la mirada situada del creador, sino de quien la mira -los modos de ver-Berger (2002). 
sorprendidas, admiradas y horrorizadas, al espectáculo de ver a quien no tenía permitido ni ser escuchado ni ser mirado, mirar de frente y a los ojos Belaustetigoitia (2001: 18) al resto de la población.

En este marco y en el desarrollo de trabajo previo García-Mingo (2013, 2014, 2015), me han surgido preguntas de investigación que trascienden al mero análisis audio(y)visual y me han llevado a preguntarme sobre: (1) el surgimiento de una cultura audiovisual indígena que trasciende los experimentos de "cámara nativa" y sus características; y, (2) sobre el impacto de la aparición de culturas audiovisuales no occidentales en nuestras orientaciones epistemológicas a la hora de trabajar con materiales audio(y)visuales. Este trabajo está dividido en dos partes: una parte introductoria en la que se reflexionan sobre las cuestiones apuntadas y una segunda parte dedicada a reflexionar sobre la cultura audiovisual indígena a partir del estudio de caso del proyecto comunicativo del Pueblo Mapuche. He optado por llevar a cabo este estudio de caso, por considerarlo en auge y escasamente descrito Salazar (2004:3).

Pese a ser un trabajo meramente descriptivo, este artículo es una reflexión que emana del trabajo etnográfico realizado por esta autora en Chile y Europa en el periodo 2012-2015. En los años 2012 y 2013 desarrollé un trabajo de investigación etnográfica sobre la radio mapuche Kimche $\mathrm{Mapu}^{4}$ (Región de los Ríos, Chile) y su uso de las ondas para reivindicar los derechos colectivos y reforzar su identidad indígena. En 2015 regresé al Wallmapu para continuar trabajando con comunicadores indígenas y conduje trabajo etnográfico con otras experiencias mediáticas indígenas como Radio Wallon (Lican Ray, Araucanía), el festival de cine indígena FIC WALLMAPU 2015 y el Encuentro de Comunicador@s Indígenas que tuvo lugar en Temuco en Noviembre de 2015. Los resultados de la observación participante y las entrevistas conducidas con comunicadores mapuche en el periodo de Septiembre-Diciembre de 2015 han sido la fuente principal de las afirmaciones que aquí se presentan. La reflexión se ha nutrido además del análisis de las declaraciones de acciones comunicativas de los Pueblos del Abya Yala, tales como el Festival de la Serpiente o la Cumbre Continental de Comunicación Indígena. El trabajo etnográfico conducido con los comunicadores indígenas ha seguido la propuesta metodológica de la etnografía colaborativa $a^{5}$ appaport (2008) la cual se basa en un proceso de coinvestigación, donde todas las partes (investigador e investigados) contribuyen activamente a interpretar y construir sentido de lo que sucede en el grupo Álvarez Veinguer y Dietz (2014: 5). Hacer este apunte es relevante para tener una coherencia investigadora, ya que este artículo eleva una crítica sobre la representación de los Pueblos Indígenas y, a su vez, no deja de ser una forma de poner a circular una nueva versión sobre la mirada y el oído indígena. 2014)

${ }^{4}$ Pueden revisarse los resultados de este trabajo en artículos publicados por la autora (2013,

5 Se puede leer una reflexión metodológica sobre etnografía colaborativa y trabajo con comunicadores indígenas en un artículo de la autora de 2015. 


\section{EL SURGIMIENTO DE UNA CULTURA AUDIOVISUAL INDÍGENA}

Los experimentos de cámara nativa que proliferaron en el siglo XX, como los conocidos casos de los Navajo documentado por Worth y Adair en Through Navajo Eyes (1977), el proyecto Video nas Aldeias en el Nordeste de Brasil Vincent Carelli (1989) o el uso de la cámara por parte de los Kayapó en los años 70 , de la mano de Terence Turner $(1992,2002)$ contribuyeron a que surgiera una producción audiovisual propia de los Pueblos Indígenas en muchos rincones del Mundo. Desde los años 60, como resultado de una transformación de las subjetividades indígenas, un aumento de la intensidad de la amenaza a su forma de vida, un mayor acceso a las tecnologías de la información, la participación en dichos talleres de apropiación Turner (1992:5) y la proliferación de debates sobre la autoría, la veracidad y las posibilidades políticas de los medios de comunicación, posibilitó que los activistas de los Pueblos Indígenas, que habían sido objetos exóticos de muchas películas, empezaron a plantearse la posibilidad de producir sus propias imágenes. Así es como surgió la cultura audiovisual indígena, que podríamos definir como una cultura audio(y)visual compartida por activistas indígenas en su camino de reivindicación de derechos colectivos.

La cultura audiovisual indígena está caracterizada por tener una agenda política que la dinamiza, una matriz epistémica que la atraviesa y una dimensión estética que la enraíza ${ }^{6}$. Así lo resumió Alberto Muenala, director quechua de Ecuador, cuando hizo la apertura del Primer Festival de la Serpiente: Este evento pretende sentar bases para la creación de una política de comunicación alternativa desde la perspectiva indígena (...) Necesitamos organizar la producción propia de videos y masificarla, construir redes efectivas de intercambios, solidarias y mancomunadas; necesitamos promover la diversidad de géneros y formatos, reconociendo todas las potencialidades de nuestras formas ancestrales de auto-representación Ossa (2013: 35). Es nuestra intención ahora examinar estas tres dimensiones.

En primer lugar, podemos afirmar que de la cultura audiovisual indígena destaca su dimensión política. Hoy, la comunicación indígena ha sido incorporada en la agenda del activismo indígena García-Mingo (2014, 2012), por ser considerada como un derecho que es clave para ejercer otros derechos fundamentales. Para Tarcila Rivera Zea, destacada lideresa quechua de Perú sostiene que tener un medio significa poder. Poder para posicionar nuestra agenda, poder para construir imaginarios sociales positivos y constructivos de lo indígena, en definitiva, poder para hablar y expresar nuestros sentires desde nosotros y nosotras mismas (2013:9). No sólo se ha ido incorporando la cuestión de la comunicación indígena en la agenda de los Pueblos Indígenas, sino que ya se puede hablar sin duda de una agenda de comunicación indígena. Esta

${ }^{6}$ Este término hace alusión a los trabajos de Ginsburg (1994) que describen la "estética enraizada" de los pueblos indígenas. 
agenda se está vertebrando mediante la realización de actividades formativas que se multiplican en el el Abya Yala y complementan los grandes encuentros del audio(y)visual indígena, como son las Cumbres de Comunicación Indígena, celebradas en 2010 (Colombia), 2013 (México) y 2016 (Bolivia).

Del elenco de conceptos que están usando actualmente los comunicadores indígenas sobre su agenda de comunicación, quiero llamar la atención sobre el concepto de soberanía audiovisual, el cual aparece en las declaraciones de las cumbres y es definido como: la producción de obras por los pueblos indígenas que se encuentran en la búsqueda de una imagen propia y plantean distintas miradas que no encuentran un espacio en la distribución comercial (Semana por la Soberanía audiovisual 2015) ${ }^{7}$. Otro concepto sugerente que está emergiendo en los discursos de los comunicadores indígenas es el de la minga de comunicación, encuentros en los que se debate o se da formación sobre comunicación, haciendo alusión a la minga (de la voz quechua mink'a), la práctica de trabajo colectivo y voluntario que existe en mucha culturas indígenas del Abya Yala.

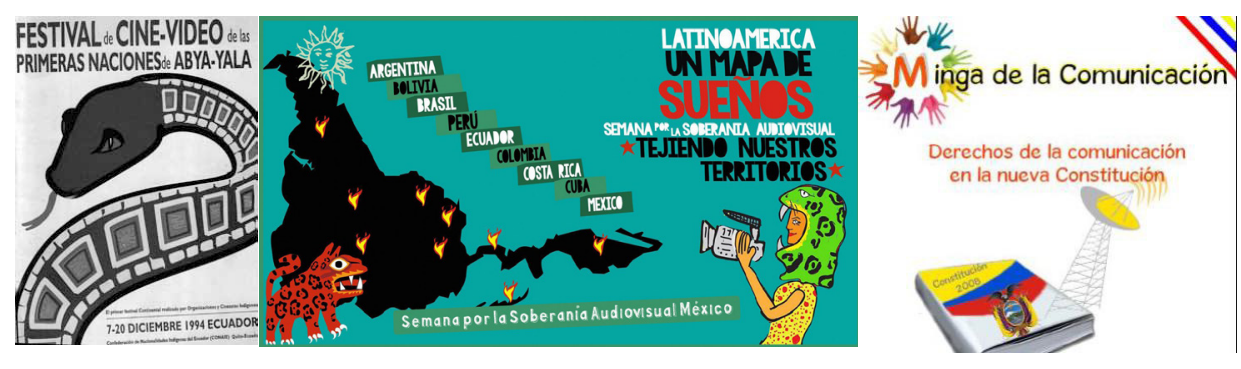

Imágenes 3, 4 y 5: Carteles de los eventos: Primer Festival de la Serpiente (Ecuador,1994), Semana de la Soberanía Audiovisual (México, 2015) y Minga de la Comunicación (Ecuador, 208).

En segundo lugar, destaca la dimensión estética de estos nuevos productos comunicativos y es que lo que arrojan los estudios Salazar (2004), Salazar y Córdova (2008), Córdova (2011), Zamorano (2009), Ginsburg (1993, 2002) es que los Pueblos Indígenas tienen una estética concreta -estética enraizadaGinsburg (1993), Córdova (2011) y una poética diferente. Juan Francisco Salazar usa el término de poética de los medios para referirse tanto al proceso (poeisis) como al producto de los mismos. Para este autor, la transformación del producto viene dada por la trasformación del proceso, y así lo defiende, refiriéndose a las palabras de Iván Sanjinés, cineasta y director del Centro de Formación y Realización Cinematográfica (Bolivia): la mirada indígena es otra mirada, conlleva una variedad de maneras de concebir lo audiovisual donde

\footnotetext{
${ }^{7}$ Sepuedeconocermásdeestainiciativaaudio(y)visualen:https://soberaniaaudiovisualmexico. wordpress.com
} 
prevalece la idea de conjunto, de comunidad, más que de individuo aislado, en donde los tiempos respetan la posibilidad de expresión y transmisión de un mensaje Salazar (2004:66).

En tercer lugar, quería destacar que la cultura audiovisual indígena se opone a la cultura audiovisual occidental también por tener una matriz epistemológica propia en su aproximación a la producción audio(y)visual. Los diferentes grupos de comunicadores o los diversos Pueblos Indígenas, han optado por diferentes metáforas, matrices y conceptos para pensar y actuar sobre la comunicación. Nos interesa reflexionar sobre este tipo de cuestiones porque tienen un gran impacto en la conformación de los códigos de representación.

Un ejemplo conocido, por su proyección global ${ }^{8}$, es el Tejido de Comunicación para la Verdad y la Vida del Pueblo Nasa. Esta red de comunicadores nació en 2005 recogiendo la experiencia e iniciativas de comunicación en la zona y asumiendo el mandato indígena y popular. Los comunicadores del Tejido de Comunicación forman parte de un telar compuesto por los cinco Tejidos de Vida del Pueblo Nasa y el objetivo de su labor no es la producción individual ni el desempeño de una profesión sino que, como afirma Edna Mena, comunicadora del mismo: ... hay que caminar la palabra, ver que estar en los medios es tejer y hacer sentir nuestra voz. No estamos en los medios solamente por estar, es para que nosotros mismos contemos nuestra historia (2013: 29).

También es interesante la experiencia de comunicadores chiapanecos que han usado la metáfora del vídeo-machete. Un coordinador del Proyecto de Medios en Chiapas cuenta que un videoasta ${ }^{10}$ indígena de un municipio autónomo zapatista le dijo que el vídeo para ellos era como un nuevo machete y a raíz de esta imagen surge la idea del vídeo-machete (Kohler, 2004:10). Esta imagen del vídeo como machete es propia del mundo rural indígena y como tal hace nuevas conexiones entre la herramienta y sus usos. Kohler apunta agudamente: de muchas maneras el machete ayuda para producir y reproducir la vida, mientras que el video facilita y potencia la comunicación (...). Por otro lado, con el machete no se produce arte, cosa no pretenden hacer los campesinos indígenas con la cámara o el vídeo (2004:10).

${ }^{8}$ Tejido de Comunicación recibió el Premio Bartolomé de las Casas en 2010

9 Ampliar es posible en: http://www.nasaacin.org/sobre-nosotros2013/estructura-cxhabwala-kiwe/54-comunicacion-y-relaciones-externas/60-tejido

${ }^{10}$ Este término es utilizado como el equivalente a video-realizador porque se utiliza reiteradamente en la literatura latinoamericana como voz similar a "cineasta". 


\section{DEL IGLOO AL VÍDEO-MACHETE: LA DECONSTRUCCIÓN DE LA MIRADA OCCIDENTAL Y LAS REORIENTACIONES EPISTEMOLÓGICAS}

El surgimiento de culturas audiovisuales no occidentales supone una oportunidad única para deconstruir (nuestra) la mirada occidental y nos obliga a hacer reorientaciones epistemológicas a la hora de trabajar con materiales audio(y)visuales. El proyecto de creación de una cultura audiovisual propia por parte de los Pueblos Indígenas es una invitación a pensar sobre cuestiones fundamentales en la investigación mediante y con materiales audio(y)visuales, tales como la violencia de la representación, las políticas de la representación, la autoría o la circulación de imágenes. El surgimiento de una cultura audiovisual indígena inaugura un nuevo punto de partida en la investigación con materiales audiovisuales porque hemos superado el momento en el que los sujetos investigados han dejado de ser objetos de investigación para tornarse en sujeto con competencia narrativa o discursiva que da voz y atribuye significación a su experiencia Baer y Schnettler (2009:7).

Aquellos que fueran objetos de investigación y luego sujetos de investigación son hoy dueños de la imagen y el sonido, como siempre lo fueron. Los Pueblos Indígenas no sólo tienen voz y atribuyen significación a su experiencia en el marco de las investigaciones y producciones occidentales, sino que la imagen ha retornado, como lo ha hecho la palabra, a quien nunca la perdió. Esta es precisamente la idea que vertebra el proyecto comunicativo del Abya Yala: Los pueblos indígenas proclamamos nuestro derecho a la creación y recreación de nuestra propia imagen. En tanto somos pueblos recíprocos, exigimos que las imágenes captadas en las comunidades indígenas, regresan a estas (Primer Festival de la Serpiente, Ecuador 1994).

John Berger nos enseñó que en la acción del ver y del mirar no sólo es importante aquel que representa, sino que también existen modos de ver, es decir, que todos nosotros, cuando somos espectadores, observadores o auditores, ponemos a trabajar un complejo entramado de subjetividad, cultura y ubicación en la estructura social. Las producciones indígenas que se están haciendo hoy en día están intentando subvertir este hecho. Están intentando descolonizar tanto nuestras miradas como la que tienen los pueblos sobre sí mismos, todos nosotros profundamente influidas por la mirada colonial de Occidente sobre el Mundo Indígena. Los Pueblos Indígenas no nos están indicando nuevos modos de ver(les) a través de sus lenguajes audio(y)visuales nuevos, sino que también están elaborando nuevos modos de verse, reconocerse y representarse.

Como espectadores, ciudadanos de un mundo globalizado, analistas y profesores, tenemos que detener sobre nuevas miradas y cines otros, que nos recuerdan que nos están mirando aquellas que fueron largamente mirados, porque, recordemos lo que vemos no vale -no vive-más que por lo que nos mira Didi-Huberman (2006:6). Entrar en contacto como espectador del audiovisual de sujetos subalternos nos hace preguntarnos qué lugar estamos teniendo en el proceso de subalternización. De esta manera, el crítico colombiano Mora 
Calderón se declara incapaz de contemplar neutralmente las obras de cine indígena, porque aunque intenta gobernar su mirada, asegura vivir un verdadero enfrentamiento cuando reconocemos que lo que nos mira tiene tanto de sujeto de nuestra mirada como nosotros tenemos de objeto de la suya (2013: 31).

La descolonización de la mirada que nos proponen los Pueblos Indígenas es una oportunidad para revisitar los grandes debates que han ocupado a teóricos del análisis audiovisual, tales como el de la objetividad/subjetividad de la imagen o el de realidad/ficción. Trabajar sobre textos audiovisuales indígenas, que precisamente denuncian lo subjetivo ${ }^{11}$ e ideológico de la producción audiovisual sobre sus vidas permite retomar estos debate con insumos nuevos para repensarlo. Veamos un ejemplo. Los pueblos indígenas no sólo han desafiado la concepción de objetividad/subjetividad de la imagen, sino que al manejar diferentes ideales de verdad a la hora de modelar sus obras de ficción Mora Calderón (2013: 133) y de documental, acaban con la contraposición verdadero/falso o fiel a la realidad/manipulado que emerge como corolario del debate objetividad/ subjetividad Serrano y Zurdo (2012: 225). En este punto, cabe mencionar el caso de las producciones de docu-ficción que realizan desde 1997 un grupo de comunicadores indígenas en Bolivia con el apoyo del Plan Nacional Indígena Originario de Comunicación Audiovisual. Estos autores están "documentando" mediante la técnica de la docu-ficción escenas relevantes de la historia y la política local, utilizando el video como una manera de «intervenir en la realidad» política del país Zamorano (2009: 259). Es una forma de desafiar los géneros existentes que separan realidad y ficción y de reinterpretar la propuesta de la docu-ficción inaugurada precisamente por el documental etnográfico. Así, los productores indígenas están logrando, con filmes realizados desde la comunidad como Llanthupi munakuy (Quererse en las sombras) (2001) o Cocanchej sutimpy (En nombre de nuestra coca) (2005), colocar su propia visión-versión de la historia, de la cultura y del mundo Reguillo (2000: 69).

${ }^{11}$ Llama la atención que la tradición del documental etnográfico, considerado un género "objetivo" que han conquistado el mito de la aprehensión de la realidad misma aspirando a la consecución del ideal de objetividad de las ciencias sociales positivas Serrano y Zurdo (2012: 225) comenzara precisamente con Nanuk, el esquimal (Robert Flaherty, 1922). En esta película no sólo se impuso la mirada colonial, sino que además fue criticado por haber ficcionado, falseado y por representar a una Nación Inuit obsoleta y desaparecida. 


\section{LA CULTURA AUDIO(Y)VISUAL MAPUCHE: UN ESTUDIO DE CASO}

En los últimos años, se ha producido un esfuerzo en el seno del Movimiento Mapuche ${ }^{12}$ para crear centros de producción de conocimiento que pongan fin a la violencia epistémica, es decir, la prohibición de explicar el mundo con códigos y referencias propias Spivak (1995: 281). Esta pretensión de descolonización tuvo un hito importante en la obra de Elicura Chihuailaf, Recado Confidencial a los chilenos (1995), el cual rompió el denso manto de silencio impuesto sobre su pueblo con un particular "recado" de los Pueblos Indígenas a la población chilena. En 2008, la publicación de la obra de los académicos mapuche i... Escucha Wingka...! continuó con la labor de retomar nuestro pasado bajo nuestra propia epistemología y construir nuevos conocimientos a partir de nuestra cultura Marimán et al. (2008: 9). Paralelamente, el trabajo del Centro de Estudios y Documentación Mapuche Liwen desde los años 90 y el surgimiento de la Comunidad de Historia Mapuche en 2004, nos permiten hablar de una red de experiencias de descolonización epistémica en el Wallmapu que tiene un compromiso con el desmantelamiento del colonialismo, el racismo y la opresión en sus variadas formas, para construir creativamente en el caminar y el hacer, rutas y modos de descolonización abiertos al diálogo con otros sujetos, pueblos e historias (Declaración del Centro de Historia Mapuche ${ }^{13}$, 2004).

Es en este marco donde debemos estudiar el trabajo de descolonización del universo audio(y)visual en Chile en el que están inmersos muchos de los medios mapuche en la actualidad. Los diarios Puelche, Mapuexpress, Mapuche Times y Azkintuwe, las radios Kimche Mapu, Radio Wallon y Werken Kvrvf, el programa radial Wixage Anai!, los blogs Werken.cl y Paismapuche.org o las producciones audiovisuales de Lulul Mawidha o ADKIMVN han surgido por la necesidad de contrarrestar estereotipos y estigmatizaciones construidas desde los grandes medios, buscando una comunicación con identidad propia. Muchas de las producciones mediáticas que se están dando en el Wallmapu o las realizadas por mapuche urbanos migrados a Santiago -los mapurbes Añiñir (2005)- buscan subvertir el proceso de colonización, diáspora y enmascaramiento identitario en el que viven muchos mapuche hoy en día Ancán y Calfío (2002). Desde la cosmovisión mapuche, la comunicación tiene un sentido particular, vinculado a cuestiones de su espiritualidad, a los elementos de la naturaleza y a las propias reglas y tradiciones relacionadas a la organización comunitaria de este pueblo Yanniello (2014: 113). En esta línea, Matías Melillán, periodista de la Radio AM Wajzugun (en Puelmapu, Argentina), explica: No queríamos reproducir la lógica winka que nos reprime. Eso fue parte del camino, de darnos cuenta que

12 Me refiero al Movimiento Mapuche como la parte del pueblo Mapuche que se ha organizado en Chile y Argentina desde los año 90 en el marco de la emergencia indígena continental y que está focalizado en la reconquista de derechos colectivos

13 Para conocer con más detalle el trabajo de la Comunidad de Historia Mapuche ver: http:// www.comunidadhistoriamapuche.org 
esa no es la construcción que queremos hacer para la comunicación mapuche Yanniello (2014: 129). Para el colectivo de Mapuexpress la comunicación y la información contribuyen a avanzar hacia el kume mogen (el buen vivir) y su rüpü (el camino a seguir) es el de la defensa de los derechos colectivos Mapuexpress (2016).

\subsection{Descolonizar el universo de la imagen desde el kimun mapuche}

John Berger nos enseñó que una obra visual es en sí misma la cristalización de un modo de ver, un modo de dar forma material a un conjunto de preferencias visuales cuyos valores se hallan culturalmente determinados (2002). Este trabajo nos recuerda que los pueblos indígenas están transformando la estética visual y sonora de sus relatos, al incorporar una estética enraizada Cordova (2011), Ginsburg (1993) basada en el hecho de que la calidad del trabajo se juzga por su capacidad de encarnar, mantener e incluso reactivar o crear ciertas relaciones sociales Ginsburg (1993: 367). Los nuevos autores de este cine otro, están operando desde una producción estética indígena colectiva, asociada al sistema de conocimiento ritual basado en el territorio y la tradición.

\section{a) Surgimiento del vídeo y del cine mapuche: de Punalka al FIC Wallmapu}

Como afirmábamos, desde los años 90, los cineastas y videoastas mapuche han creado una nueva poética de los medios, la cual está atravesada por la dimensión política de su proceso: es política la vocación de su producción, es político el proceso de producción debido a la voluntad de apropiación y es política la gestión de la distribución de los productos. Para comprender la producción audiovisual mapuche es necesario echar la vista atrás sobre la productora audiovisual mapuche que se estableció en Santiago de Chile en los años 90, Lulul Mawidha y su principal realizadora: Jeannette Paillán. Esta documentalista mapuche ha destacado por su obra documental Punalka (1995), Wallmapu (2002), Sin embargo, no sólo tiene una obra interesante, sino que además es vehículo de un activismo muy notable en el audiovisual indígena, habiendo sido coordinadora general de CLACPI (Coordinadora Latinoamericana de Cine Producción Indígena) y ahora directora del FIC WALLMAPU. Resumiendo la vocación eminentemente política del cine mapuche y siendo uno de sus principales exponente, ella concluye: no hago películas para mostrar lo que está ocurriendo... hago películas para cambiar la situación del Pueblo Mapuche (en De la Tierra a la Pantalla, Salazar 2004).

Otro de los agentes fundamentales de dinamización del audiovisual en el Wallmapu es ADKIMVN, una organización mapuche que surgió en 2003 con el fin de hacer producción audiovisual así como otras acciones de comunicación (festivales, talleres, reportajes, spots...). ADKIMVN cuenta con un portal web 
y un canal en Youtube, pero destaca sobre todo su producción audiovisual, querealiza en coproducción con lof (comunidades mapuche ancestrales) con el fin de rescatar y proteger la cultura mapuche. Algunos de sus títulos detacados son: Pewen Mongen Taiñ Pu Che (2010), Itrofillmongen (2007) y Luchando por nuestros derechos (2012).
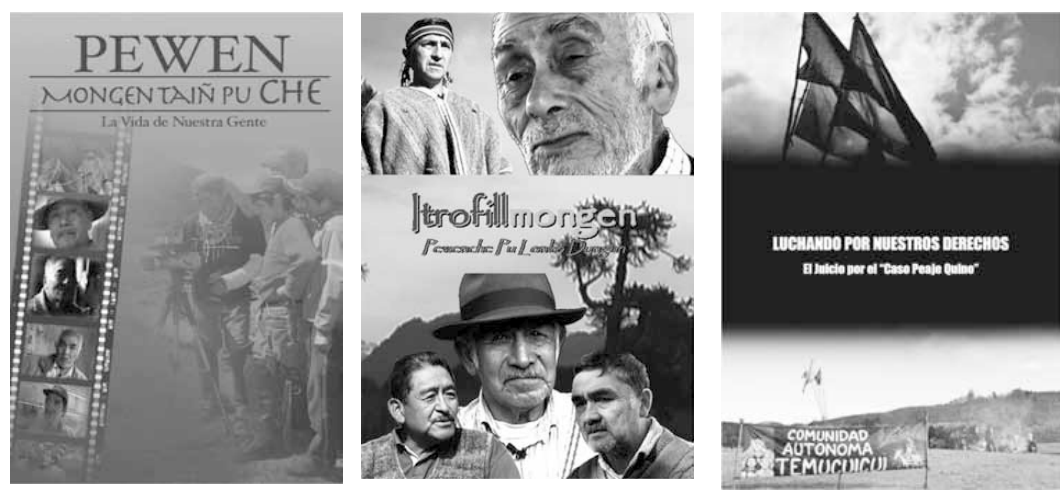

Imágenes 6, 7 y 8: Películas mapuche producidas por ADKIMVN: Pewen Mongen Taiñ Pu Che (2010), Itrofillmongen (2007) y Luchando por nuestros derechos (2012)

Por último, quería destacar la labor de formación y producción que se está haciendo desde en la Escuela de Cine y Comunicación Mapuche del Aylla Rewe Budi, la cual se fundamenta en el tukulpa kimvn o traer el conocimiento a través de la reflexión entorno a la comunicación mapuche. De esta forma tomamos el cine como herramienta para trabajar y reflexionar sobre diversos aspectos de nuestra cultura. Desde 2011 en esta escuela, que tiene lugar cada verano, varios jóvenes mapuche de diferentes lof se forman con comunicadores mapuche y miembros de la organización candiense Wapikoni Mobile y se implican en la creación colectiva de cortos cinematográficos que luego se distribuyen en muestras itinerantes y festivales. Algunos títulos destacados son: Lafken $\tilde{N} i$ $A z$ (El océano revela su conocimiento) (2016), Challwan Kvzaw (El arte de la pesca) (2015) y Pu papay ñi kimvn (La sabiduría de nuestras abuelas) (2015).

Como adelantaba, con su agenda de comunicación indígena, el Pueblo Mapuche pretende incidir en todas las fases de la comunicación, incluida la política de distribución, por este motivo se ha creado recientemente una Red de Comunicadores Mapuche, un festival de cine propio y una serie de actividades en torno al festival (muestras, talleres, conferencias...). En 2015 se realizó por vez primera en territorio ancestral mapuche el festival internacional de cine y vídeo indígena FIC WALLMAPU. Éste se guía por un kimün (filosofía) que se compone, entre otros, de los siguientes principios: 
- El cine y el video indígena son instrumentos poderosos que ayudan en la lucha por la expresión propia y el verdadero desarrollo de los pueblos originarios.

- Esta forma de expresión tiene raíces profundas, pues transmite mensajes milenarios de nuestras culturas que viven y conviven con la tierra.

- El cine y el video indígena son medios para compartir saberes que hemos recibido de los más antiguos.

Además del trabajo del festival, cuyo fin es constituirse como un espacio para fomentar el diálogo intercultural, que constituye un proceso social y cultural que sin duda es muy relevante para el territorio y también un aporte a las relaciones interculturales a nivel mundial, convocando a realizadores de Chile, América y el mundo, en torno al desarrollo y producción del cine y las artes con temática indígena (organización del FIC WALLMAPU), el audiovisual de corte indígena se está expandiendo gracias a las Muestras Itinerantes de Cine Indígena por todo el territorio.
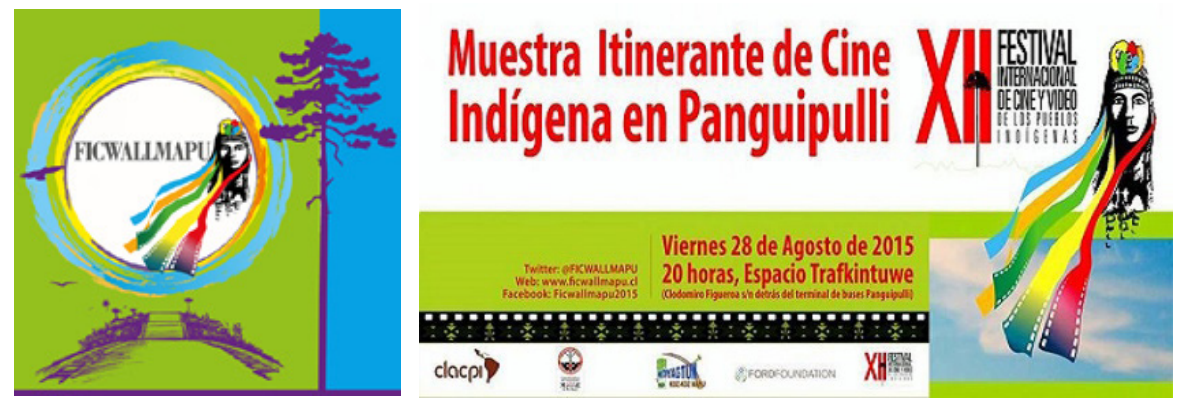

Imágenes 9 y 10: Carteles del Festival FIC Wallmapu 2015 y de una de las muestras de cine itinerante en el territorio mapuche (Chile)

Estas proyecciones en diferentes puntos del territorio ancestral son una apuesta política de la organización del festival y tienen por principal objetivo fomentar la mirada reflexiva multicultural, el respeto por la diversidad y la valoración de nuestros Pueblos Indígenas, a través de la exhibición de realizaciones audiovisuales en distintos territorios de Wallmapu.

\section{b) El kimun del audiovisual en Wallmapu y la transformación de la iconografía mapuche}

Desde que comenzaran a producir películas propias en los año 90, como Punalka (Jeannette Paillán, 1995) o Wiñometun ñi Mapu meu (José Ancán, 1994), los comunicadores mapuche están reivindicando la posibilidad de crear desde el kimün, sabiduría mapuche. Para Jeannette Paillán, los micrófonos, las cámaras 
de video, de foto son una herramienta que se puede colocar en favor de los pueblos indígenas cuando, especialmente, son manejados por nosotros mismos porque le damos una mirada distinta, una óptica distinta" (en Correa, 2014). Cabe recordar que, a pesar de estar en un proceso de descolonización, se produce en un complejo proceso político en el que también los imaginarios nacionalistas, raciales y de género se recrean, reproducen y transforman Zamorano (2005:22), generando una "mirada indígena" plural, cambiante y, por supuesto, en diálogo e hibridación con la mirada hegemónica. Para Gabriela Chihuailaf, crítica de cine mapuche, el traspaso de la opinión "justa" de lo que se "tenía" que decir por parte de los cineastas no indígenas de antaño se ve reflejado hoy, en un cine documental indígena donde se da la palabra a quien quiera expresarla, pero rigiéndose por el formato y la estética del género documental (2014).

Podemos afirmar que además de tener una poética concreta, se está produciendo una estética audiovisual mapuche compartida por muchas de las producciones de ADKIMVN, la Escuela de Aylla Rewe Budi, Lulul Mawidha y otras producciones independientes. Esta estética está caracterizada, en primer lugar, por trabajar fundamentalmente en el género del documental, no sólo porque es menos costoso y difícil de ejecutar, sino porque para quienes hacen cine en Wallmapu, tienen entronque con prácticas de la oralidad mapuche (epew, ulkantun, pewma...) así como la sociabilidad mapuche (ceremoniales, nutram, trawun...) de tal manera que permite desarrollar los temas de interés de la sociedad mapuche a través de la palabra y la conversación. Por otro lado, casi todas las películas mapuche realizadas en los últimos veinticinco años han tenido el interés de recuperar o dignificar prácticas culturales propias y de denunciar situaciones como el extractivismo o la violencia policial. Sin embargo, se están empezando a producir cortometrajes y lagometrajes de animación, que están produciendo una trasformación del lenguaje cinematográfico mapuche, como es el caso del corto de animación Nahuel, una leyenda mapuche (Jesús Sánzhez, 2015).

Otro de los rasgos fundamentales del cine y el vídeo mapuche, que deriva del hecho de que el género preferido sea el documental, es el uso del testimonio. En todas las películas aparecen personas que dan su testimonio mientras se sucede el conjunto de imágenes, planos, secuencias, de tal manera que así se resuelve la estructura de lo que se quiere decir en el relato fílmico Chihuailaf (2014). El testimonio requiere usar constatantemente el plano fijo de retrato, lo cual hace que el uso del plano fijo sea un rasgo característico de la estética del cine mapuche Chihuailaf (2014), Por otro lado, el sonido es muy característico en el audiovisual mapuche, puesto que, como en los paisajes sonoros que se construyen y difunden en las radios indígenas, recurren a los recursos de la oralidad y la música tradicional mapuche, así como el uso del mapudungun. Un rasgo fundamental de la estética del cine mapuche, como otros productos del cine indígena es el montaje de las imágenes; las películas son realizadas con una manera de editar que imprimen un ritmo a sus imágenes muy diferente al convencional, lo que provoca en el espectador una sensación diferente que la que tiene cuando ve películas de factura de Hollywood, puesto que el tiempo en la 
cultura mapuche es el de la Naturaleza y las largas ceremonias y reuniones.

El kimun mapuche también está vertebrando otras producciones audiovisuales mapuche; de hecho, se está produciendo también una transformación de la iconografía mapuche más allá del lenguaje audiovisual. Muchos movimientos sociales, así como el arte urbano, combinan elementos gráficos de la modernidad occidental con símbolos de la cosmovisión mapuche. Este es el caso de la plataforma ciudadana NOALDUCTO, la cual lucha desde hace 20 años contra la construcción por parte de la forestal Celulosa Arauco (CELCO) de un conducto de vertidos tóxicos en la costa del Mar de Mehuín (Océano Pacífico). Este es el caso de los productos audiovisuales de los movimientos sociales mapuche, los cuales, en línea con la estética audiovisual, combinan elementos ancestrales (hombres mapuche tocados por trarilonkos, bandera wenufoye, el tambor ritual mapuche) y elementos del discurso global, como el discurso ecologista marcado por elementos como el pez contaminado o el tubo de vertidos:
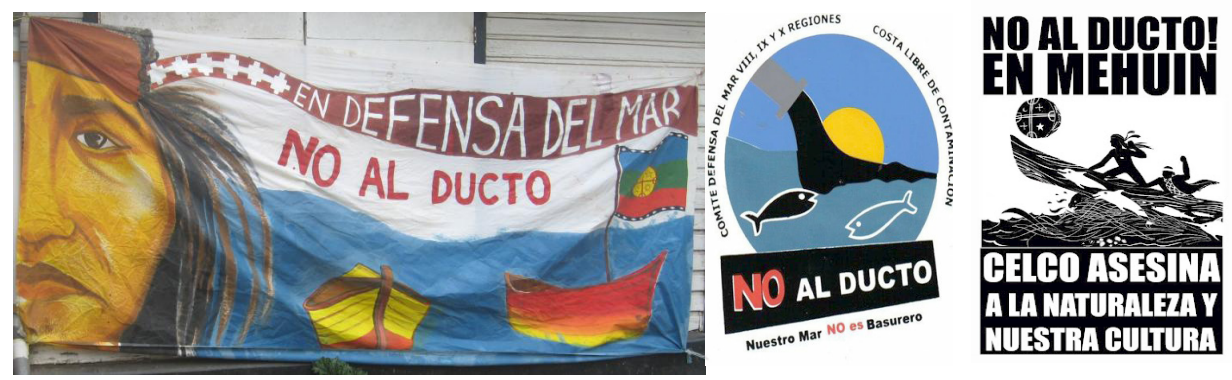

Imágenes 11, 12 y 13 : Carteles del movimiento social de las comunidades mapuche lafkenche del Mar de Mehuín NO AL DUCTO

Más allá de los movimientos sociales y del arte urbano, se puede apreciar la inclusión del kimun y otros elementos de la cosmovisión mapuche en otros artefactos visuales como es la caricatura, el diseño gráfico y el cómic. Diversos periódicos mapuche como MapucheTimes o el diario chileno The Clinic, están salpicados de viñetas de Pedro Melinao, dibujante mapuche que se dedica al humor gráfico y al cómic. 

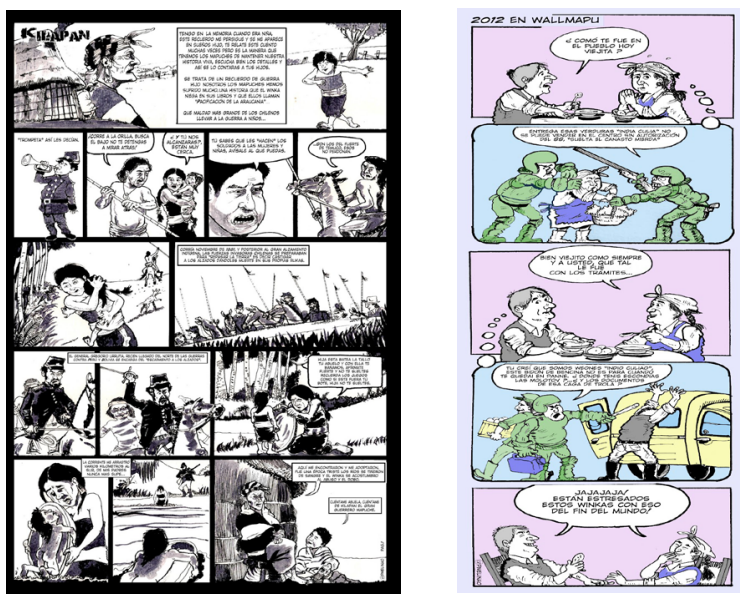

Imagen 14 y 15: Cómic Histórico Mapuche (2016) y Humor Mapuche (2012)

Este autor fue muy criticado cuando comenzó a publicar viñetas sobre el Pueblo Mapuche y recibió la acusación de estar haciendo algo que nunca había sido propio de los mapuche. Sin embargo, éste afirma que el formato del cómic se asemeja mucho a los relatos mapuches porque aunque en ellos hay harta oralidad, también hay gestos. El orador mapuche, aparte de contar la historia que narra, también la actúa (Melinao entrevistado en Vidal, 2009). Como Melinao, muchos autores mapuche del área del diseño, el arte, la comunicación y los videojuegos ${ }^{14}$ se están sumando a la producción audiovisual, generando nuevos códigos y lenguajes que están contribuyendo a relatar e interpretar la modernidad mapuche.

\subsection{El sonido del kullkull. El fin de la asimilación sónica mapuche.}

Trabajar sobre descolonización del oír en el Wallmapu nos permite reivindicar el lugar de lo sonoro -lo audio- en el análisis de "lo audiovisual". Para Murray Schafer, creador del concepto de paisaje sonoro (1977), en la episteme de Occidente, el oído ha ido perdiendo de forma gradual su primacía como sentido para conocer el Mundo. Así se ido generando un sistema óculocentrista que crea una jerarquía sensorial en las formas de construir y fijar el conocimiento Reis (2007). Ahora se hace es necesario reconocer que existen otras epistemes en las que otros sentidos desempeñan un papel central en fenómenos sociales como las identidades, la memoria colectiva o la interacción social. Este artículo en un tímido intento de contribuir a intentar comprender

14 Es muy interesante el caso de Wichan (2009), un juego de cartas mapuche que fusiona el uso de las tecnologías de la información y comunicación con el conocimiento ancestral mapuche. 
cómo la escucha desempeña un papel en el modo en que las personas se relacionan entre sí como sujetos a través de medios físicos, sensitivos y especialmente auditivos Earlman (2004:2-3).

En una cultura determinada por el predominio de lo visual, apenas prestamos atención a las experiencias sonoras; sin embargo, el sonido puede traernos un flujo de imágenes a la mente despertando una memoria multisensorial. El Pueblo Mapuche, con su exilio en su propio territorio, ha vivido una pérdida de la identidad aural López-Gil (2007) con la trasformación de su estilo de vida. Las radios mapuche en Lican Ray, Lanco, Temuco, Galvarino, Concepción o Santiago, pretenden con su programación recrear esos paisajes sonoros del Wallmapu, utilizando lo sonoro como elemento de transmisión de emociones. A través de la radio, muchos mapuche se pueden reconstruir a sí mismos en la intimidad de sus hogares. El sonidos de los kultrun, el kullkull o la trutuka, la voz de los kimche narrando los epew (cuentos) en mapudungun y el canto de los ulkantun (cantos mapuche) forman parte de un paisaje sonoro que en la ciudad es imposible escuchar, y así, se abre paso un reconocimiento de una identidad, de un lugar, de un sueño. Esos sonidos ocupan el espacio, definen y esculpen un espacio acústicamente: son los retratos de la música y la poesía del paisaje sonoro de un lugar El Haouli (2007), en este caso, del Wallmapu. Durante muchos años, los mapuche han experimentado una suerte de asimilación sónica, un colonialismo acústico propagado por los medios masivos criollos CárcamoHuechante (2013: 51).

\section{a) Interferencias mapuche en la radiosfera: radios comunitarias mapuche}

Cuando Mireya Manquepillán, directora de la Radio Mapuche Kimche Mapu, es interrogada por la motivación que le llevó a crear la radio comunitaria rural e indígena en un lof mapuche en Lanco (Chile) en 2011, asegura que en la radio nunca había nada que quisiera escuchar, porque sus preocupaciones, sus historias y su realidad nunca aparecían en las emisoras radiales García-Mingo (2012:57). La mayoría del público (nativo o no) que escucha radio indígena rara vez oye la experiencia indígena reflejada en otras fuentes de radiodifusión; así es como se inscribe, también en el universo sonoro, el silencio.

Como en el caso de Radio Kimche Mapu, muchos de los medios de comunicación de corte indígena más exitosos que se han creado en Chile son radios. Esto se debe a que tienen una relación gasto-beneficio conveniente, usan un lenguaje comprensible para la población analfabeta y encajan en las lógicas narrativas de la tradición oral. Con la radio indígena, el público recibe un enfoque informado sobre lo que concierne al pueblo indígena y a sus comunidades. En la mayoría de estas emisoras se habla de temas como la preservación del medio ambiente y la recuperación de prácticas ancestrales, se dan programas de humor nativo, se programa música propia o se dan prácticas culturales propias, como es el caso del trueque, el trafkintu, en el 
Pueblo Mapuche. Las radios mapuche constituyen una interferencia indígena Cárcamo-Huechante (2013) en la sonosfera criolla chilena, en dos sentidos: porque están interfiriendo políticamente, rompiendo el silencio impuesto sobre las reivindicaciones políticas del Pueblo Mapuche y porque al incluirlas en las ondas, se está convirtiendo performativamente a la lengua, los relatos familiares y las narraciones de la oralidad mapuche en audibles en el universo sonoro colonizado Cárcamo-Huechante (2013: 65).

Las radios mapuche, a ambos lados de Los Andes están comprometidas en la reemergencia étnica del Pueblo Mapuche Yanniello (2014), Cárcamo-Huechante $(2013,2010)$, lo cual se está traduciendo en la recuperación de paisajes sonoros y marcas sonoras locales propias del territorio ancestral mapuche. Algunas radios mapuche de cierta trayectoria como Radio Kimche Mapu o Radio Werken Kvrrvf (Lago Budi) y programas radiales como Wixage anai! (emitido en Santiago a través de Radio Panamericana) están ejerciendo una resistencia sonora a la asimilación sónica que viven, tanto los mapuche de las comunidades como la población que ha abandonado comunidad de origen. La "interferencia" en el espacio sonoro va encaminada a recuperar sonidos que tienen la capacidad simbólica de definir el espacio y la relación del sujeto con el espacio Carles (2007), en este caso, a llevar de vuelta a todos los mapurbe (mapuche urbano) a su territorio ancestral en Wallmapu.

$\mathrm{Al}$ (re)producir paisajes sonoros mapuche en las ondas, los programas de radio están contribuyendo a construir un sentido indígena de pertenencia colectiva al un pueblo largamente postergado. Cárcamo-Huechante, intelectual indígena, entiende que las narraciones radiofónicas que se están produciendo están simbólicamente enmarcadas en la metanarrativa del Wallmapu (la nación mapuche) Cárcamo-Huechante (2013: 58). Estas mediaciones son muy relevantes debido a la pérdida de memoria que vive el Pueblo Mapuche, tiene que suplirse con una nueva narrativa, en palabras de Anderson: cuando una identidad no puede ser recordada tiene que ser narrada (2011 [1983]: 284). Recordemos que así la radio está colaborando a la construcción de la utopía del retorno al país mapuche Ancan y Calfío (2002: 20) ya que son efectivos en la construcción de la comunidad imaginada Anderson (2011 [1983]: 23).

Por otro lado, una labor eminentemente política y de interferencia que están haciendo las radios es la de la recuperación (más allá de los temas y las demandas) de las formas de habla y de oralidad mapuche. Tanto la lengua mapuche, el mapudungun 15 , como las formas narrativas orales mapuche han sido constantemente excluidos en la mediasfera chilena y argentina. Cabe destacar que en la cultura mapuche, la palabra -dungun- tiene un poder performativo, porque no sólo es creadora de interacciones habladas y de textos, sino que también desencadena recuerdos, crea nuevos sujetos y establece intersubjetividades, restaura ritualmente la salud individual y configura el bienestar -kime feleal- y la fuerza comunitaria -newen- e incentiva procesos activos de comunalización Golluscio (2006). Pese a ser tan importante para su

15 La palabra (dungun) de la tierra (mapu) 
pueblo, el mapudungun se está extinguiendo a una velocidad alarmante. Las radio mapuche, al incorporar la lengua ancestral dignifican su uso en la esfera pública, la arrojan de la tierra a las ondas para transformar la representación que de ellos se hace en las radios convencionales. Es decir, que la palabra hablada se está convirtiendo en palabra radiada, que puede ser registrada, difundida y reproducida.

\section{b) Los rasgos del nuevo paisaje sonoro mapuche: de la oralidad a la radi(o)ralidad}

Para Schafer, el paisaje sonoro se construye a partir de sonidos específicos que hacen que un lugar sea identificable, él los denomina huellas sonoras locales (soundmarks). (1994: 239). Los criterios en función de los cuales seleccionamos los sonidos que nos llegan proviene en gran medida, del modo en el que escuchamos lo que nos rodea Atienza (2007), es decir, que no sólo existen modos de ver como afirmaba Berger, sino también modos de oír. Éstos van asociados, entre otras cosas, a la identidad sonora. El conjunto de elementos sonoros característicos son parte indisociable de un lugar y constituyen la identidad sonora de un lugar y quien lo habita, o lo ha habitado, puede identificarlo a través de los sonidos que lo caracterizan. El sonido, por tanto, es inseparable del entorno social que lo provoca y de la geografía que lo abraza. Es precisamente a partir de estas ideas, que trabaja el lenguaje radiofónico, puesto que la radio fue concebida como una forma de establecer sociabilidades y (re) construir identidades Reis (2007: 12). Para Karla Berrens, que se ha ocupado de estudiar la relación entre el sonido, el cuerpo y el espacio, los sonidos son parte de los procesos de dotar de sentido al espacio (y la vida social) de las personas y moldean las relaciones de las personas con los espacios y, más aún, esta vivencia de los lugares contextualiza de manera muy aguda las maneras en las que las personas constituyen sus identidades Berrens (2015: 73).

La comunidad imaginada se construye, en gran parte, a partir de una memoria e identidad compartida y por ello, los programas de radio mapuche, construyen paisajes sonoros, que transportan a los sujetos en el espacio (de retorno al Wallmapu) o, en el tiempo (el pasado que se fue). Estos programas guardan una cierta regla estética que se puede caracterizar por incluir ${ }^{16}$ : el uso de la lengua mapuche, música cantada en mapudungun, sonidos de instrumentos tradicionales, sonidos de la naturaleza, recursos narrativos de la oralidad mapuche -como son los epew, relatos orales de la ancestral cultura mapuche y el ulkantun, cantos tradicionales-, fragmentos de testimonios en primera persona y el gritos de demostración de fuerza característico del pueblo mapuche como, el afafan.

${ }^{16}$ Como ejemplo se puede escuchar el programa Caleidoscopio (UACH Radiolina): http:// podcastcdn-16.ivoox.com/audio/4/5/1/8/caleidoscopio24mayo2016-radiouniversidadaustralchileivoox11708154.mp3? secure=fwfhGssCiLkv31u9PYP68w==,1466200248 
Los programas radiales, así como el sonido de las producciones audiovisuales, suelen comenzar con el sonido de instrumentos tradicionales mapuche como la trutruka, el trompe, el kultrun o el kullkull, como es el caso del programa Wixage Anai!, que abre con la llamada del kull kull, un instrumento de viento que se asocia a la convocatoria de las personas en las ceremonias mapuche y que remite a momentos rituales muy poderosos dentro de la cultura mapuche. La música es un rasgo sonoro esencial de los paisajes sonoros indígenas, puesto que la resistencia que se está dando a la asimilación sónica también pasa por la recuperación o la creación de música propia. Este es el caso del proyecto Cantando as Culturas Indígenas, desarrollado en 2012 por la organización Thydewá en el nordeste brasilero, con más de una decena de pueblos indígenas. El proyecto consiste en la producción y grabación de un $\mathrm{CD}$ con canciones de música ancestral así como en la redacción de un libro explicativo del uso de la música en este grupo de culturas indígenas, porque como explican los protagonistas: intentaron exterminar todos los pueblos indígenas, pero nosotros resistimos y resistimos también a través de los cantos. Los cantos son registros históricos socioculturales de los indígenas en la vida de la Madre, perpetuados musicalmente Gerlic (2012).

El periodista mapuche argentino Kvrvf Nahuel (de Mapuradio) afirma que para el Pueblo Mapuche la comunicación está vinculada con otras cuestiones como pueden ser la educación o la música. De hecho, uno de los rasgos distintivos del lenguaje radial mapuche es la inclusión del canto tradicional mapuche (ülkantun), como en el caso del programa Wixage Anai!, reconocido programa mapuche. En esta producción radial, como explica CárcamoHuechante, habitualmente se interpreta el ül en las ondas, siendo éste un canto tradicional de la cultural oral y musical mapuche (2013: 62). Por ejemplo, se invita a participar en el programa a mujeres ancianas que interpretan el güman ülkantun, una canción de tristeza Cárcamo-Huechante (2013: 62) que remite lo perdido y lo pasado, lanzando así a las ondas un lamento por aquello que fue arrebatado y nunca podrá ser repuesto.

El equipo de Mapuradio (en Argentina) creó precisamente un grupo de música, Puel Kona, para acometer el rescate del sonido mapuche: Investigamos mucho sobre el tema, porque cada sonido para nosotros tiene un sentido. Entendemos a la música como una expresión milenaria de nuestra cultura Yanniello (2014: 124). Por este motivo, en las radios, no sólo se incluye el ülkantun sino que también se programa música mapuche contemporánea de raíz folclórica como la de Cecil González, Rubén Patagonia, Daniela Millaleo o Beatriz Pichimalen, así como de música híbrida, es decir, géneros occidentales cantados en mapadugundun como es el rock o el hip hop de Brocas de las Naquis, Kolectivo We Newen o Luanko ${ }^{17}$, el cual trata, a través de sus canciones en español y en mapudungun temas como el racismo, la represión del estado, la cuestión de los presos mapuche o los problemas asociados al extractivismo en territorio mapuche, lo que él define como un hip-hop con mensaje mapuche.

17 Para ver su trabajo visitar: https://www.youtube.com/watch?v=mgwrokWOkiE 

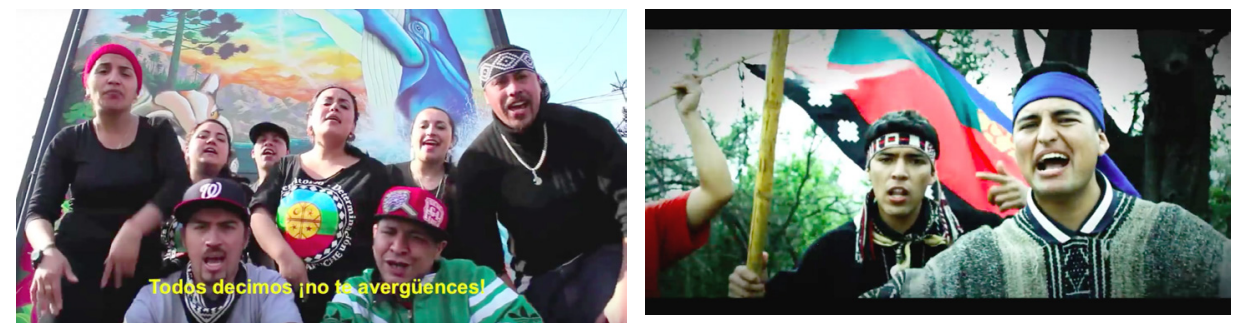

Imágen 16 y 17: Vídeoclip de la canción Mapudungunfinge (de Wechekeche Ni Trawun) y Rap de la Tierra (Luanko)

Otro grupo que suele aparecer con sus canciones en las ondas mapuche es Wechekeche Ni Trawun, puesto que han publicado seis discos desde su creación en 2004 de temas que fusionan la música tradicional mapuche con diversos ritmos urbanos (hip-hop, cumbia, reggae...) incorporando letras contestatarias sobre los conflictos de las comunidades mapuche y los conflictos identitarios que viven los jóvenes indígenas urbanos. Para Jacob Rekedal, profesor de la Universidad de La Frontera que ha estudiado el tema, el hip-hop mapuche anuncia la emergencia nuevas redes de información e identificación, las cuales articulan las luchas antiguas de la Araucanía con las poesías de resistencia provenientes de culturas distantes (2014: 28).

\section{A MODO DE CONCLUSIÓN}

Este artículo ha pretendido reflexionar acerca de el trabajo político, estético y epistemológico que están haciendo Pueblos Indígenas para indicarnos nuevos modos de ver(les) a través de lenguajes audio(y)visuales nuevos y de nuevos modos de verse, reconocerse y representarse. Por tratarse de un trabajo descriptivo y especulativo, no puede hablarse de hallazgos o resultados, pero sí se pueden subrayar las líneas fundamentales de reflexión que han vertebrado el artículo. Estas son:

(1) Desde los años 90, en el marco de la emergencia indígena Bengoa (2000), ha surgido una nueva cultura audiovisual indígena, la cual he definido como una cultura audio(y)visual compartida por activistas indígenas en su camino de reivindicación de derechos colectivos. Para llevar a cabo la tarea de describir esta cultura audiovisual emergente, he repasado someramente sus dimensiones, que son:

(a) La dimensión política de la cultura audiovisual indígena: Esta dimensión hace referencia al hecho de que la comunicación indígena ha sido incorporada en la agenda del activismo indígena García-Mingo (2014, 2012), por ser considerada como un derecho que es clave para ejercer otros derechos fundamentales. 
(b) La dimensión estética de la cultura audiovisual indígena: Se refiere a que las producciones indígenas no sólo tienen una factura particular -es una estética enraizada- Ginsburg (1993), Córdova (2011)- si no que tiene una poética propia, es decir también un proceso de producción audiovisual basada en la cosmovisión indígena.

(c) La dimensión epistemológica de la cultura audiovisual indígena: Indica el hecho de que los comunicadores indígenas han optado por diferentes metáforas, matrices y conceptos para pensar y actuar sobre la comunicación, las cuales son relevantes para configurar sus códigos de representación.

(2) Por otro lado, el artículo reflexiona sobre la oportunidad que supone el surgimiento de culturas audiovisuales no occidentales para deconstruir (nuestra) la mirada occidental y para hacer reorientaciones epistemológicas a la hora de trabajar con materiales audio(y)visuales y con sujetos subalternizados.

(3) Además, en el estudio de caso sobre el Pueblo Mapuche, se ha hecho una revisión somera del trabajo audio(y)visual que se está desarrollando en el Wallmapu -territorio ancestral mapuche- como parte de un esfuerzo global de descolonización y confrontación con la violencia epistémica que proviene del régimen colonial. Este trabajo tiene dos vertientes:

(a) Cine y video mapuche: Mediante un intenso trabajo de producción, formación y distribución, los cineastas y videoastas mapuche están trabajando en la elaboración de un universo visual propio. Además, se ha explicado que la mirada y el oído que se está produciendo como parte del proyecto político del retorno al Wallmapu y descansa en el kimun mapuche, desde la voluntad de hacer visible su propio pensamiento, así como sus temas, sus formas formas de organización y su sentido de la belleza.

(b) El paisaje sonoro mapuche: Se están desarrollando nuevos paisajes sonoros mapuche, que aúnan las marcas sonoras locales de la vida antigua en el Wallmapu (los sonidos de la naturaleza), así como nuevos lenguajes sonoros, como música híbrida y contemporánea, que ayudan a la comunidad mapuche en la diáspora a reconocer(se) como mapuche o mapurbe. Las radios mapuches se han convertido en uno de los espacios donde se expresan las formas de sentir y nombrar el mundo propio Cruz y Huerta (2015: 20), mediante la recuperación de la música tradicional, el mapudungun y las formas narrativas de la oralidad mapuche. Este hecho resulta ser un acto político muy potente, puesto que han sido tradicionalmente excluidas de la sonosfera chilena y argentina.

Este trabajo también ha sido un esfuerzo reflexivo sobre el aporte que supone la aparición de una nueva cultura audiovisual al trabajo epistemológico, metodológico y analítico de aquellos interesados en las metodologías audio(y) visuales. Es una invitación a pensar sobre la imagen y el sonido como un 
instrumento de dominación, pero también de emancipación individual y colectiva. Hoy, más que nunca, lo audio(y)visual es espacio social donde los sujetos y los colectivos subalternos están subvirtiendo los procesos subalternización. Nuestra tarea como investigadores es seguir trabajando para descolonizar nuestra mirada y entender las imágenes como las entiende el kimun mapuche del Festival de Cine Indígena del Wall Mapu: una forma de hacer visible nuestro pensamiento, nuestras formas de organización y nuestro sentido de la belleza.

\section{REFERENCIAS}

ÁLVAREZ VEINGUER, Aurora y DIETZ, G. (2014) Etnografía colaborativa: coordenadas desde un proyecto en curso. Actas del XIII Congreso de Antropología. Antropología y Descolonialidad. Tarragona: FAAEE y Universidad Rovira i Virgili.

ANCÁN, José y CALFÍO, Margarita (2002): "Retorno al País Mapuche. Reflexiones sobre una utopía por construir". Working Paper Series 6. En Internet: http://www. mapuche.info/wps_pdf/ankalfio020300.pdf.

ANDERSON, Benedict (2011[1983]) Comunidades Imaginadas. México: Fondo de Cultura Económica.

AÑINIIR, David (2005) Mapurbe venganza a raíz. Santiago: Odiokracia Autoediciones.

ATIENZA, Ricardo (2007) Ambientes sonoros urbanos: la identidad sonora. Modos de permanencia y variación de una configuración urbana. I Encuentro Iberoamericano de Paisaje Sonoro. Madrid, 12-15 de Junio. En: http://cvc.cervantes.es/artes/ paisajes sonoros/p sonoros01/atienza/atienza 01.htm

BAER, Alejandro y SCHNETTLER, Bernt (2009) "Hacia una metodología cualitativa audiovisual. El vídeo como instrumento de investigación social". En: Merlino, Aldo (Ed) Investigación Cualitativa en las Ciencias Sociales: Temas, problemas y aplicaciones. Buenos Aires: Cengage Learning. Pp. 149-173

BENGOA, José (2000) La emergencia indígena en América Latina. Santiago: Fondo de Cultura Económica.

BARRIENDOS, Joaquín (2008): "La colonialidad del ver. Hacia un nuevo diálogo visual interepistémico" Nómadas (Col), núm. 35, octubre: pp. 13-29

BERGER, John. (2002) Modos de ver. Barcelona: Gustavo Gili

BERRENS, Karla. (2014). «Urban sonic cartographies». Bifurcaciones: revista de estudios culturales urbanos. Num. 18, ISSN.0718-1132.

BELAUSTEGUIGOITIA, Marisa (2001): "Descaradas y deslenguadas: el cuerpo y la lengua india en los umbrales de la nación". Debate Feminista, Vol. 24 (12).

CÁRCAMO-HUECHANTE, Luis (2013) "Indigenous Interference: Mapuche Use of Radio in Times of Acoustic Colonialism." Latin American Research Review. Vol. 48, Special Issue, 2013. 50-68.

CARLES, José Luis (2007) El paisaje sonoro, una herramienta interdisciplinar: análisis, creación y pedagogía con el sonido. I Encuentro Iberoamericano de Paisaje Sonoro. Madrid, 12-15 de Junio. En: http://cvc.cervantes.es/artes/paisajes sonoros/p sonoros01/carles/carles 01.htm

CÓRDOVA, Amalia (2011) "Estéticas enraizadas: aproximaciones al video indígena en América Latina". En Comunicación y Medios (24). Instituto de la Comunicación e Imagen, Universidad de Chile, 2011. 
CORREA, Julián (2013) "Miradas que aportan a nuestra historia y a la historia del cine" En DAUPARÁ, Catálogo razonado de Daupará: Muestra de Cine y Video de los Pueblos Indígenas de Colombia. Págs: 13-16.

CARELLI, Vincent (1989) "Video in the Villages: Utilization of Video-Tapes as an Instrument of Ethnic Affirmation Among Brazilian Indians", in CVA (Commission on Visual Anthropology) Newsletter, pp. 10-15.

CHIHUAILAF, Elicura (1995) Recado confidencial a los chilenos. Santiago de Chile: LOM.

CHIHUAILAF QUILAQUEO, Gabriela (2014) "El Cine, una cuestión de travelling". YEPAN, Revista Digital de Cine y Comunicación Indígena. En: http://www.yepan. cl/yepan-apuntes-sobre-cine-el-cine-una-cuestion-de-travelling/

CHIRAPAQ (2013) Racismo, medios de comunicación y Pueblos Indígenas. Lima: SINCO.

CURIVIL, Ramón (2008) La fuerza de la religión de la tierra: una herencia de nuestros antepasados. UCHS, Santiago de Chile.

DAUPARÁ (2013) Catálogo razonado de Daupará: Muestra de Cine y Video de los Pueblos Indígenas de Colombia. Bogotá: IDARTES.

DE MIGUEL, Jesús y PONCE, Omar (1999) "Para una sociología de la fotografía". Reis: Revista española de investigaciones sociológicas, $\mathrm{N}^{\circ} 84,1998:$ 83-124

DIDI-HUBERMAN, George (2006) Lo que vemos, lo que nos mira. Buenos Aires: Manantial.

Declaración de la Cumbre Continental de Comunicación Indígena de Abya Yala (2010).

Cumbre Continental de Comunicación Indígena de Abya Yala, Noviembre 2010. En: http://www.cccia-2010.com/.

EARLMAN, Veit (2004) Hearing Cultures. Essays on Sound, Listening and Modernity. Oxford: Berg.

EL HAOULI, Jeanete (2007) Paisajes sonoros de Brasil: experiencias interdisciplinares. I Encuentro Iberoamericano de Paisaje Sonoro. Madrid, 12-15 de Junio. En: http:// cvc.cervantes.es/artes/paisajes sonoros/p sonoros01/haouli/haouli $01 . \mathrm{htm}$

GARCÍA-MINGO, Elisa (2014) "Persiguiendo la Utopía: medios de comunicación mapuche y la construcción de la utopía del Wall Mapu". Anuario Deusto de Derechos Humanos, Num. 12/2014:161-184

GARCÍA-MINGO, Elisa (2012) "Voces de la Tierra: Derecho a la Información en el movimiento pro-derechos de los Mapuche en Chile". DERECOM, No. 12. Diciembre-Febrero, 2013.

GERLIC, Sebastian. (2012) Cantando as Culturas Indígenas. Coordenaçao Geral de Educaçao Escolar Indígena. Coleçao Índios ba Visao dos Índios

GINSBURG, Faye, ABU-LUGHOD, Lila. y LARKIN, Brian. (2002). "Introduction." En Media Worlds: Anthropology on New Terrain. Los Angeles: University of California Press. Pp 1-31.

GINSBURG, Faye (1991). "Indigenous Media: Faustian Contract or Global Village?" En Cultural Anthropology No 6 (1): 92-112

GINSBURG, Faye (1994) "Embedded aesthetics: creating a space for indigenous media". En: Cultural Anthropology 9 (3): 365-382

GOLlUSCIO, Lucía (2006) El Pueblo Mapuche: Poéticas de pertenencia y devenir. Buenos Aires: Biblios.

HERNÁNDEZ, Franco (2012). "Política de comunicación indígena, características y compromisos. 2012: Año Internacional de la Comunicación Indígena”. En Internet: http://www.mapuexpress.net/?act=publications\&id=7011 
HUERTA, Erick y CRUZ, Blanca (2015) Haciendo Milpa. Estrategias de apoyo a la formación de comunicadores indígenas. México DF: REDS.

KOEHLER, Axel (2004) Nuestros antepasados no tenían cámaras: el video como machete y otros retos de la video-producción indígena en Chiapas, México. Revista Chilena de Antropología Visual, no 4, Julio: pp. 391-406.

LÓPEZ-GIL, Juan (2007)“La auralidad consensuada. Paisaje sonoro y redes sociales". I Encuentro Iberoamericano de Paisaje Sonoro. Madrid, 12-15 de Junio. En: http:// www.unruidosecreto.net/textos/texto-la-auralidad-consensuada/

MARIMÁN, Pablo; CANIUQUEO, Sergio; MILLALÉN, José y LEVIL, Rodrigo (2006) ¡...Escucha, winka...! Cuatro ensayos de Historia Nacional Mapuche y un epílogo sobre el futuro. Santiago de Chile: LOM Ediciones.

MENA, Edna (2013) "Comunicación, proyecto político y construcción colectiva de paradigmas". En CHIRAPAQ (2013) Racismo, medios de comunicación y Pueblos Indígenas. Lima: SINCO. Pp. 29-32.

MILLACURA, Claudio (2015) “¿Encubrimiento o Descubrimiento?”. Material del curso «Nuevas miradas sobre Género y Etnicidad», impartido en UAbierta, Universidad de Chile.

MUENALA, Alberto (1995). "Cinema as an instrument for indigenous peoples identity," Felix: A Journal of Media Arts, No 1, Vol. 2. Pp. 154-156.

MORA CALDERON, Pablo (2013) Nuestras miradas. En DAUPARÁ, Catálogo razonado de Daupará: Muestra de Cine y Video de los Pueblos Indígenas de Colombia. Pp. 17-34.

OSSA ARIAS, Leornarda (de la)(2013) "Imágenes desde la raíz: Los pueblos indígenas de Colombia en torno a la imagen audiovisual del Abja Yala". Revista Fundación Friedrich Ebert Stiftung-Comunicación. ANÁLISIS No11/2013. En: http://www. fesmedia-latin-america.org/uploads/media/Análisis 11.2013 - Imágenes desde la ra\%C3\%ADz.pdf

REIS, Filipe (2006) Comunidades Radiofónicas. Um estudo Etnográfico sobre a rádio local em Portugal. Dissertação de Doutoramento. Lisboa: ISCTE.

RIVERA ZEA, Tarcila (2013) "Preámbulo" En CHIRAPAQ (2013) Racismo, medios de comunicación y Pueblos Indígenas. Lima: SINCO. Pp: 9-13.

SALAZAR, Juan Francisco (2004) Imperfect Media: The Poetics of Indigenous Media in Chile. Tesis doctoral en comunicación y medios. Dir: H. Cohen. University of Western Sydney.

SALAZAR, Juan Francisco y CÓRDOVA, Amalia (2008). "Imperfect Media and the Poetics of Indigenous Video in Latin America." En Global Indigenous Media: Cultures, Practices and Politics. Durham: Duke. Pp. 39-57.

RAPPAPORT, J. (2008) "Beyond Participant Observation: Collaborative Ethnography as Theoretical Innovation", Collaborative Anthropologies 1: Pp.1-31. http://muse. jhu.edu/journals/collaborative anthropologies/v001/1.rappaport.html

REGUILLO, Rossana. (2000) "El espejo cóncavo y la irrupción indígena: movimientos sociales y comunicación". Revista de la Universidad del Valle de Atemajac. UNIVA, Guadalajara, México. Mayo-Agosto 2000.

REKEDAL, Jakob (2014) "El Hip-Hop mapuche en las fronteras de la expresión y el activismo". Lengua y Literatura Indoamericana, n 16 , 2014: 7-30

RODRÍGUEZ, Clemencia (2001) Fissures in the Mediascape. An International Study of Citizens' Media. Cresskill, NJ: Hampton Press.

SPIVAK, Gayatri. (1998) "Can the subaltern speak," en Marxism and the Interpretation of Culture, Chicago, University of Illinois Press. 
SCHAFER, M. (1977) The tuning of the world. Toronto: McClelland and Steward SERANO PASCUAL, Araceli y ZURDO ALAGUERO, Ángel (2010) "Investigación social con materiales visuales" en ARROYO, Millan y SÁDABA, Igor (coord.) Metodología de la Investigación Social: Innovaciones y aplicaciones. Madrid: Síntesis. Cap.10. Pp: 217-250

TURNER, Terence, 1992, "Defiant Images: The Kayapo appropriation of video", en Anthropology Today, Vol. 8, Num. 6. Pp. 5-16.

TURNER, Terence. (2002). "Representations, Politics, and Cultural Imagination in Indigenous Video: General Points and Kayapo Examples.” En Media Worlds: Anthropology on New Terrain. Berkeley: University of California. pp 75-89.

VIDAL, Vladimir (2009) Pedro Melinao: el gracioso de la tribu. En: http://argentina. indymedia.org/news/2009/06/678360.php

WORTH, Sol y ADAIR, John (1997 [1977]) Through Navajo Eyes: An Exploration in Film Communication and Anthropology. Indianapolis: Indiana University Press.

YANNIELLO, Florencia (2014) Descolonizando la palabra. San Carlos de Bariloche: La Caracola.

ZAMORANO, Gabriela (2005). "Community Video and Self-representation." Entrevista a Carlos Efraín Pérez Rojas." Native Networks/Redes Indígenas. Smithsonian National Museum of the American Indian. Obtenido el 12 de diciembre de 2011 en http://www.nativenetworks.si.edu/esp/rose/efrain c interview.htm\#open.

ZAMORANO, Gabriela. 2009. "'Intervenir en la realidad': usos políticos de videos de ficción y comunicación indígena en Bolivia". Revista Colombiana de Antropología. 5 (2): pp. 259-285. 


\section{FILMOGRAFÍA}

PAILlÁN, J., dir. (1995). Punalka: El Alto Bío Bío. Chile: Lulul Mawida.

PAILLÁN, J., dir. (2002). Wallmapu. Chile: Lulul Mawida.

SALAZAR, Juan Francisco (2004). De la Tierra a la Pantalla. Australia/Chile: Moai Films.

FLAHERTY, R. J. (Director) (1922). Nanuk el Esquimal. EEUU-Francia: Les Frères Revillon.

CÁRDENAS, M. (Responsable). (2001). Llanthupi munakuy. Bolivia: CEFREC-CAIB.

CLAROS, H. (Responsable). (2005). Cocanchej sutimpy. Bolivia: CEFREC-CAIB. BERROCAL, G . (2010) Pewen Mongen Taiñ Pu Che. Chile: David NahuelhualGerardo Berrocal.

BERROCAL, G. (2010) Itrofillmongen. Chile: Adkimvn.

BERROCAL, G. (2012). Luchando por nuestros derechos. Chile: Comunidad Autónoma Temucuicui-ADKIMVN

ESCUELA DE AYLLA REWE BUDI (2016) Lafken Ñ $i$ Az. Chile: Escuela de Aylla Rewe Budi-Wapikoni Mobile.

ESCUELA DE AYLLA REWE BUDI (2015) Challwan Kvzaw. Chile: Escuela de Aylla Rewe Budi-Wapikoni Mobile.

ESCUELA DE AYLLA REWE BUDI (2015) Pu papay ñi kimvn. Chile: Escuela de Aylla Rewe Budi-Wapikoni Mobile. 
